\title{
Determinants of institutional factors on the cost of climate change adaptation/mitigation programs in south-eastern, Nigeria.
}

\author{
Unaeze H.C ${ }^{1}$ and Okoye C.U $\mathrm{U}^{2}$ \\ ${ }^{I}$ Department of Agricultural economics and extension, Faculty of Agriculture, university ofPortHarcourt, \\ Riversstate, Nigeria. \\ ${ }^{2}$ Department of Agricultural economics, Faculty of Agriculture, university of Nigeria, Nsukka, EnuguState,
} Nigeria.

\begin{abstract}
This study was carried out to investigate the institutional factors that affects the cost of climate change adaptation/mitigation programs in south-eastern, Nigeria. A total of 360 respondents were randomly sampled and their opinion drawn based on their awareness level of institutions that are into climate change adaptation/mitigation programs in the study area. The twenty-six institutions identified by the respondents was sampled in order to achieve the stated objectives. Data were collected using a well-structured questionnaire and personal interview. Descriptive statistics and doubled log multiple regression analysis were used in the assessment. The result revealed that, majority of the institutions sampled, 61.5 percent obtained their funding from local/state/federal/World bank while majority 46.2 percent channel 4 to 6 adaptive/mitigation packages to rural farmers and 88.5 percent claimed that these packages are of high quality. The coefficients of staff training, institutional location $(P<0.1)$ and institutional years in climate change adaptation/mitigation support $(P<0.1)$ are positively and statistically significant in the cost of climate change adaptation/mitigation programs while access to security $(P<0.05)$, age of the institution or years of existence $(P<0.05)$ are statistically significant but negative, while staff strength $(P<0.05)$, institutional type $(P<0.05)$, institutional budgets and the number of times data are accessed by the institutions are not statistically significant in the cost of climate change adaptation/mitigation programs in the study area. Government and other financial institutions should make credit available to various institutions and institutional articulation and access should be encouraged among institutions and farming households in the study area.
\end{abstract}

Keywords: Institutional factors, Climate Change, Adaptation/Mitigation, Cost, South-eastern, Nigeria.

\section{Introduction}

Climate change is expected to affect farmers output and water resources that are vital for livelihood, in developing countries where much of the population, especially the poor rely on local supply systems that are sensitive to climate variations (Dewit \& Stankiewicz, 2006; International Institute for Sustainable Development, 2007). Climate change will be pivotal in redefining development in the twenty-first century. How nations, societies, communities and household's responds to the impact of climate changes and variability to which the world has already been committed will in many instances determine their prospects for growth, equity and sustainability (World Bank 2010).

Enete and Amusa (2010), agreed that climate change is the most serious environmental threat to economic development and can only be resolved through the intervention of institutions which are humanly created formal and informal mechanisms that shape social and individual expectations, interactions and behavior. These institutions can be classified as public (bureaucratic, administrative units, and elected local government), civic (membership and cooperative organizations) and private sectors (service and business organizations) (Uphoff \& Buck, 2006).McGray \&Youba Sokona, (2012) affirmed that institutions are the formal and informal organizations through which society structures shared decision-making and takes collective action. Institutions help to define climate change both as a problem and a context, through such socialized devices as the use of scientific knowledge, culturally defined interpretation of scientific findings and politically tolerable adaptation strategies (O'Riordam et al., 1998). Adaptation is defined as initiatives and measures to reduce the vulnerability of natural and human systems against actual or expected climate change effects (Intergovernmental Panel on Climate Change, 2007), while mitigation to climate change involves actions that are designed to limit the amount of long-term climate change effect (Fisher et al, 2007). It is widely agreed that there is a limit to what adaptation can achieve and that mitigation measures must be undertaken in parallel to prevent the negative impact of climate change on agricultural practices (IPCC 2008). But the existing international and local institutions that are available for supporting adaptation and mitigation actions in developing countries like Nigeria fall far short of what is required. (McGray \& Youba Sokona, 2012). The region should enhance institutional capacity to make better use of existing and potential international and local funding sources (GriegGran, 2006). This is because; the pathways by which economic and sectorial reforms can influence climate 
policy depend on the existing institutional framework. With appropriate institutions, a high degree of consistency between development and climate policies can be achieved and without these, there will be considerable dissonance of our farmers towards solving, the problem of climate change on their agricultural practices (World Bank, 2008). At this point it becomes pertinent to ask the following questions: What is the source, level and quality of external climate change adaptation/mitigation support and interventions packages that local institutions channel to rural farmers? What is the cost to local institutions of running the activities that relate to promotion of climate change adaptation/mitigation programs? Finally, what are the institutional factors that affects the cost of running the activities of climate change adaptation/mitigation programs among institutions in the study area?

\section{Materials And Methods}

The study was conducted in south-eastern state of Nigeria.South-East geopolitical zone of Nigeria is made up of five states. These states are Abia, Anambra, Ebonyi, Enugu and Imo States. The area has a total population of about 16381,729 million people (Nigerian Population Commission, 2006). Its land area is about 16,000sq millimeters $(40,000 \mathrm{~km} 2)$ and receive between 2000 and 3000 millimeters of rain per year.

It is the homeland of Kwa speaking people and the domain language of the region is Igbo while Christianity and African Traditional Religion (ATR) are religious that dominate the area. Majority of the inhabitants are farmers who practice farming enterprises ranging from crop production to livestock breeding, forestry, fisheries and agricultural produce processing (lloeje, 1981).

Ikeme (2009), also reported that Nigeria which southeastern is one of the geo-political zones is currently experiencing increasing incidence of diseases, declining agricultural productivity, increasing number of heat waves, unreliable or erratic weather patterns, flooding and so on. Climate change is making some land uninhabitable and affecting water supplies, threaten peoples basic needs and triggering displacement in the region. In the same vain (Njoku, 2008) noted that south eastern, Nigeria are faced with serious environmental problems as a result of human activities and natural phenomena with less prospect for economic development. Some of these problems include gully erosion; flooding; pollution; improper waste management in rural and urban centers; loss of flora and fauna, etc.

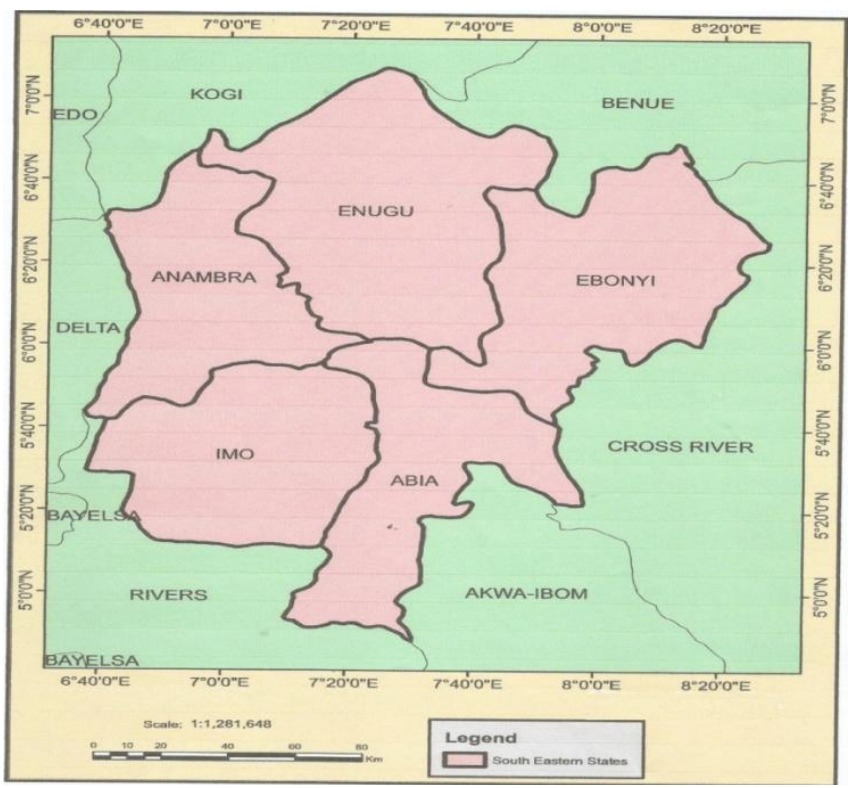

Figure 1. Map Showing South-- Eastern States of Nigeria.

\section{Result And Discussions}

1.0 Assessment of sources, level and quality of external climate change adaptation/mitigation support that local institutions channel to rural farmers.

From table1 that evaluate the sources, level and quality of external climate change adaptation/mitigation support and interventions that local institutions channel to rural farmers in the study area shows that among the 26 sampled local institutions, majority $(61.5 \%)$ agreed that their funding sources came from local/state/federal government and the World Bank. It was only (3.8\%) who agreed that their funding are from international NGOs. This fact was supported by World Bank (2009) who asserted that United Nations Framework Convention on Climate Change (UNFCCC) identified that Global Environmental facility (GEF) administered Special funds that amounted to US\$ 270 million for special Climate Change Funds (SCCF) to 
support adaptation and mitigation projects in all developing countries like Nigeria with a large emphasis on adaptation. Other support identified by World bank (2009) includes United Nations Framework Convention on Climate Change (UNFCCC) to Nigeria, as well as other 10 developing countries, under the National Economic Empowerments and Development Study (NEEDS) initiative to facilitate the identification of priority mitigation and adaptation measures and how these measures can be effectively supported financially by various sources (global and national) of funding or investment. Also Federal Ministry of Agriculture and Rural Development (FMARD), on behalf of the Federal Government of Nigeria (FGN), signed a Memorandum of Understanding with an international NGO called Sasakawa Africa Association (SAA) for collaboration. This led to the formulation of FMARD-SAA Extension Program in Nigeria referred to as, FMARD-WAAPP. (West Africa Agricultural Productivity Program) project, funded by World Bank. This projects enables farmers and extension agents get trained on best agricultural practices. The states under this program are Anambra, Benue, Cross River, Gombe, Katsina and Ogun .While FMARD released \$ 967,484 plus 6 vehicles and 60 motorbikes, WAAPP released \$398,773 to SAA. Also African Cassava Agronomy Initiative (ACAI) project which kicked off on 27 January, 2016, with plans to improve the livelihoods and incomes of cassava farmers in Nigeria, Ghana, Tanzania, Uganda, and DR Congo through research and tapping into and implementing best agronomic practices as a result of climate change. The project, which is led by IITA with funding support from the Bill and Melinda Gates Foundation, will specifically improve cassava yields, root quality, supply to the processing sector, and fertilizer sales, thereby engaging over 100,000 households in Nigeria and Tanzania, and facilitating the engagement of at least 30\% women farmers. "The value of benefits from this project in Nigeria and Tanzania is projected to be over US\$27 million. The ACAI initiative is placed within the context of intensification of cassava-based systems with a focus on the development of cassava agronomy recommendations to improve the productivity and quality of cassava roots in Nigeria, Tanzania, Ghana, and Uganda, major cassava-producing countries in West and East Africa, and some spillover into East DR Congo. The project will be in phases, starting in Nigeria and Tanzania in years 1 and 2, and will expand to the other countries from year 3 onwards. This counterpart funding has shown that there is synergy between local and international NGOs in channeling support to rural farmers.

Looking at the Level of climate change adaptation/mitigation supports packages channeled to rural farmers, majority $(46.2 \%)$ of the local institutions channeled 4 to 6 packages to rural farmers. Only (15.4\%) channeled above 6 packages. This indicates that local institutions play more active role in channeling adaptation/mitigation supports packages to rural farmers. The quality of external adaptation/mitigation packages doled out by various institutions were assessed by administering an open ended questionnaire to institutions. Their responses shows that majority $(88.5 \%)$ of the local institutions agreed that the packages are of high quality, only $(11.5 \%)$ agreed that they are of low quality, based on farmers assertion.

Table 1: Frequency distribution of the sources, level and quality of external climate change adaptation/mitigation support and intervention packages that local institutions channel to rural farmers.

\begin{tabular}{|l|l|l|}
\hline \multirow{2}{*}{ Sources } & \multicolumn{2}{l|}{ Local institutions } \\
\cline { 2 - 3 } & Frequency & Percentage \\
\hline Local/State / Federal/World & 16 & 61.5 \\
\hline Federal./ World bank & 2 & 7.7 \\
\hline State/Federal/Arabic bank & 3 & 11.5 \\
\hline Federal and NGOs & 2 & 7.7 \\
\hline State, Federal and IFAD & 2 & 7.7 \\
\hline NGOs. & 1 & 3.8 \\
\hline Total & 26 & 100 \\
\hline Level of climate change adaptation/mitigation supports and interventions \\
packages institutions channeled to rural farmers. & 38.5 \\
\hline 3 Packages and below. & 10 & 46.2 \\
\hline 4 to 6 packages. & 12 & 15.4 \\
\hline Above 6 packages. & 4 & 100 \\
\hline Total & 26 & 88.5 \\
\hline Institutions' thought on the quality of the external interventions \\
\hline High quality & 23 & 11.5 \\
\hline Low quality & 3 & 100 \\
\hline Total & 26 & \\
\hline
\end{tabular}

Source: Researcher's Field Survey, 2016

\subsection{Cost of Running the Activities that Relate to Promotion of Climate Change Adaptation /Mitigation by Local Institutions in the study area.}

Also in table 2 below, majority (76.9\%) of the local institutions spent 10 million Naira and below to promote climate change adaptation/mitigation programs. Only (19.2\%) spent above 30 million naira. This finding has shown that the required financial resources by local institutions for adaptation/mitigation strategies 
are severely limiting. It is in consonance with the findings of Enete and Amusa (2010) who stated that local institutions are faced with inadequate funds to combat climate change problems.

Table 2: Frequencies and percentages cost to local institutions of running the activities that relate to promotion of Climate change adaptation/mitigation strategies.

\begin{tabular}{|l|l|l|}
\hline $\begin{array}{l}\text { Amount local institutions have spent to promote } \\
\text { climate change adaptation/mitigation strategies. }\end{array}$ & Frequency & Percentage \\
\hline 10 million Naira and below & 20 & 76.92 \\
\hline 11 to 20 million Naira & 1 & 3.85 \\
\hline 21 to 30 million Naira & 0 & 0 \\
\hline Above 30 million Naira & 5 & 19.23 \\
\hline Total & 26 & 100 \\
\hline
\end{tabular}

Source: Researcher’s Field Survey, 2016

\subsection{Factors that determine the cost of running the activities of Climate change adaptation/mitigation program among the institutions, in the study area.}

Double log multiple regression was selected as the lead equation owing to the number of significant variables and the coefficient of determination $\left(\mathrm{R}^{2}\right)$ to estimate the effects of institutional factors on the cost of running the activities that relates to climate change adaptation/mitigation programs among institutions in the study area. From the result, Staff Strength coefficient is positive 0.20 but insignificant at $5 \%$ probability level, indicating that an increase in staff strength will not have a significant increase in the cost of running the activities that relates to climate change adaptation/mitigation programs among institutions. This finding does not agree with a priori expectation, as recruitment of staffs are supposed to increase cost of adaptation/mitigation program me. The counter intuitiveness of this facts is that most of the adaptation/mitigation funds come in form of foreign aid or grants that are specifically budgeted for, so increasing staffs strength are not always encouraged. Years of existence of institutions into climate change adaptation/mitigation programs is negative (1.54) but significant at $5 \%$ probability level. This asserts that years of existence do not have positive effects on the cost of adaptation/mitigation program me, meaning that an increase of 1 year in the age of an institution reduces the cost of delivery of adaptation/mitigation by 1.54 naira. Institutional annual budget was found to be positive and statistically insignificant at $5 \%$ probability level. This indicates that budget allocation has insignificant effects on the cost of running the activities that relates to climate change adaptation/mitigation programs among institutions. Institutional location is positive (0.92) and significant at $10 \%$ probability level, implying that the more an institution is located in rural areas the more the cost of running the activities that relates to climate change adaptation/mitigation programs among institutions. This is because most of the climate change adaptation/mitigation programs are in favor of the rural farmers who produce at subsistence level. Also number of times data on previous adaptation/mitigation programs are accessed by an institution is positive with coefficient of (1.02) but insignificant at 5\% probability level. This result has shown that number of times data are accessed by an institution do not increase cost of adaptation/mitigation program.

Years in climate change adaptation/mitigation support is positive with coefficients of (0.67) at $10 \%$ probability level. This findings has shown that as number of years an institution is engaged in climate change adaptation/mitigation support Programme increases, the more the cost of running the activities. This findings suggests that institutions involved in this program, should always apply best practices in climate adaptation/mitigation programs that will possibly attract more funding. Access to security is negatively significant with coefficient of (-1.18) at 5\% probability level. This is surprising and counter-intuitive because the expectation is that access to security supposed to increase adaptation/mitigation cost, but in this case, access to security does not increase the cost of running the activities that relates to climate change adaptation/mitigation programs. This might be that institutional access to security will reduce possible attacks by hooligans, angry village youths, and kidnappers on the administrators and program support packages that will eventually reduce cost of adaptation/mitigation program. Number of staff training is statistically significant and positive (1.24) at $10 \%$ probability level. This result has shown that as staff training increases, the more the cost of running the activities that relates to climate change adaptation/mitigation programs. This finding is consistent with a priori expectation. Finally coefficient of determination $\mathrm{R}^{2}$ results has shown that $87 \%$ of the cost of running the activities that relates to climate change adaptation/mitigation programs among institutions are explained by the explanatory variables included in the model.

Table 3.0 Regression result of the factors that determine the cost of running the activities of Climate change adaptation/mitigation program among the institutions.

\begin{tabular}{|l|l|l|l|}
\hline \multirow{2}{*}{$\begin{array}{l}\text { R Square and Variables in } \\
\text { the Model }\end{array}$} & \multicolumn{2}{|l|}{ Coefficients (probability value) } \\
\cline { 2 - 4 } & Linear Regression & Semi-log Regression & Double-log Regression \\
\hline $\mathrm{R}^{2}$ & $0.97(0.00)^{*}$ & $0.89(0.00)^{*}$ & $0.87(0.00)^{*}$ \\
\hline Staff Strength & $69342.85(0.68)$ & $3.29(0.11)$ & $0.20(0.73)$ \\
\hline
\end{tabular}




\begin{tabular}{|l|l|l|l|}
\hline Years of existence & $-326859.6(0.79)$ & $-7.35(0.00)^{*}$ & $-1.54(0.01)^{*}$ \\
\hline Institutional type & $-2.20(0.38)$ & $-3.44(0.34)$ & $-0.12(0.91)$ \\
\hline Budget & $0.23(0.00)^{*}$ & $2282102(0.70)$ & $0.26(0.16)$ \\
\hline Institutional location & $2.52(0.04)^{*}$ & $5.86(0.00)^{*}$ & $0.92(0.05)^{* *}$ \\
\hline $\begin{array}{l}\text { Number of times data was } \\
\text { accessed by the institution }\end{array}$ & $-588895(0.40)$ & $3.92(0.08)^{* *}$ & $1.02(0.11)$ \\
\hline $\begin{array}{l}\text { Years in climate change } \\
\text { adaptation/mitigation support }\end{array}$ & $-1105747(0.58)$ & $4.79(0.01)^{*}$ & $0.67(0.15)^{* *}$ \\
\hline Access to security & $-3484976(0.81)$ & $-3.42(0.07)^{* *}$ & $-1.18(0.04)^{*}$ \\
\hline $\begin{array}{l}\text { Number of institutional staff } \\
\text { training }\end{array}$ & $2594007(0.02)^{*}$ & $4.67(0.06)^{* *}$ & $1.24(0.08)^{* *}$ \\
\hline Constant & $-2.98(0.05)^{* *}$ & $-2.46(0.03)^{*}$ & $8.23(0.02)^{*}$ \\
\hline
\end{tabular}

Source: Researcher's Field Survey, 2016

Note: $*$ Significant at $5 \% ; * *=$ Significant at $10 \%$, NS $=$ Not significant at $5 \%$ $(\mathrm{F} ; 9,14)=10.33,(0.0001)$.

\section{Summary}

The summary divulges thatmajority of the institutions (61.5\%) agreed that their funding sources came from local/state/federal government and the World Bank and there is counterpart funding between public institutions and international NGOs. This has shown that there is synergy between local and international NGOs in channeling support to rural farmers. Majority (76.9\%) of the local institutions spent 10 million Naira and below to promote climate change adaptation/mitigation programs, while $(88.5 \%)$ of the local institutions agreed that the packages doled out to farmers are of high quality, only (11.5\%) agreed that they are of low quality, based on farmers assertion. Double log multiple regression was selected as the lead equation owing to the number of significant variables and the coefficient of determination $\left(\mathrm{R}^{2}\right)$ to estimate the effects of institutional factors on the cost of running the activities that relates to climate change adaptation/mitigation programs among institutions in the study area. The model showed that the coefficients of staff training, institutional location $(\mathrm{P}<0.1)$ and institutions' years in climate change adaptation/mitigation support $(\mathrm{P}<0.1)$ are positive and statistically significant in the cost of running the activities that relates to climate change adaptation/mitigation programs among institutions, while access to security $(\mathrm{P}<0.05)$, age of the institution or years of existence $(\mathrm{P}<0.05)$ are statistically significant but negative. Surprisingly staff strength $(\mathrm{P}<0.05)$, institutional type $(\mathrm{P}<0.05)$, institutional budgets and the number of times data are accessed by the institutions are not statistically significant in the cost of climate change adaptation/mitigation programs among institutions in the study area.

Based on the findings of this study, the following recommendations are outlined:

- Government and other financial institutions should make credit available to farmers because the major challenge constraining them to adapt/mitigate to climate change is lack of fund. The availability of this fund will help them boost their farm productivity.

- Farmers should be trained on how to apply the adaptive/mitigate packages given to them.

- Institutional access and articulations should be encouraged among farming households and institutions in order to adapt/mitigate favorably to climate change.

\section{References}

[1]. Ajibefun, A.A (2002).Analysis of policy issues in technical efficiency of small-scale farmers using the stochastic frontier production function, with applications to Nigeria farmers. Paper presented at the IFMA Congress, wageningen, Netherlands, July 11.

[2]. Anselm A. Enete and Taofeeq A. Amusa (2010).Challenges of Agricultural Adaptation to climate change in Nigeria: a synthesis from the literature: Institute Veolia Environment (4).

[3]. De Wit, m and stankiewicz, J. (2006). Changes in surface water supply across Africa with predicted climate change. Science 311, 1917-21.

[4]. Fisher, J, Linden Mayer DB, and Manning AD. (2006): Biodiversity, ecosystem function and resilience: ten guiding principles for off reserve conservation. Front Ecology Environment 4:80-86.

[5]. Grieg-Gran, M. (2006).The cost of Avoiding Deforestation: Report prepared for the Stern Review of the economics of climate change. International Institute for Environment and Development (IIED), London, UK.

[6]. IISD (International institute for sustainable Development) (2007) Community based adaptation to climate change Bulletin. A summary of the second International Workshop on Community Based Adaptation to Climate Change. IISD Reporting services.

[7]. Ikeme J. (2009). Assessing the future of Nigeria's Economy: Ignored threats from the global climate change debate. Africa Economic analysis Vol.1 (2).

[8]. Iloeje NP (1981). A new Geography of Nigeria. Longman, Nigeria.

[9]. IPCC (2007) Summary for policymakers on climate change 2007: Impacts Adaptation and Vulnerability contribution of working Group II to the fourth Assessment Report of the Intergovernmental panel on climate change.

[10]. McGray \&Youba Sokona (2012): Why Institutions Matter For Climate Change Adaptation In Developing Countries: World Resources.

[11]. Njoku, J.D. (2008). Effects of Landover Change on Vegetation in South Eastern Nigeria. PhD thesis, Geography, Owerri, Imo State University. 
[12]. O'Riordan, T, Marria, C. Langford I. (1997). Images of Science Under-laying Public Perceptions of risk. In Blewitt, J. (ed), Science, Risk and Policy Royal Society London.

[13]. Okoro,F.U.(1987 Change Agent Role in technological transfer process to facilitate peasant farmers productivity; InUmeh,P.O.C et al(eds.,Increasing productivity in Nigeria(Pp.454-461.Proceedings of the First National Conference on Productivity, National Productivity Center, Abuja.

[14]. The World Bank annual report (2008): Year in review. 